\title{
Single stream versus two stream recycling: an examination of costs and recovery rates of current programs in Ontario, Canada
}

\author{
D. Lantz \\ Solid Waste Management, GENIVAR Ontario Inc., Canada
}

\begin{abstract}
In 2006, the approximately 12 million residents in the province of Ontario, Canada recycled almost 940,000 metric tonnes of material representing about $192 \mathrm{~kg} /$ household, up from $181 \mathrm{~kg} /$ household in 2005. The manner in which these materials are collected and processed varies across the 200 municipalities, but can be primarily broken down into single stream and two stream (fibres and containers) programs. Within the province, the debate continues over whether to go single stream or continue with two stream for the collection and processing of recyclables.

Although larger programs have tended to go to single stream recycling under the promise of lower costs, higher recovery and ease for residents, recent research in Ontario suggests that single stream is not providing the direct benefits that municipalities expected. Costs are higher than anticipated. Recovery rates are not typically higher than for two stream programs. Perhaps, more importantly, product quality issues, particularly with the fibres from single stream programs have caused such problems with the paper mills, there is a strong indication that downgrades and significantly lower revenues for newspaper could be coming in the very near future. The lost revenues from higher value containers inadvertently being shipped in the fibres stream increases net costs further.

This paper examines single and two stream recycling programs in Ontario, sharing recent data on the relative cost differentials (and why they exist) between the two types of programs. Finally, a potential solution to product quality that those municipalities that have adopted the single stream recycling approach have to address will be introduced.
\end{abstract}

Keywords: recycling, economic analysis, single stream, two stream, recovery rates, recyclables revenues, product quality. 


\section{Introduction}

There has been an ongoing debate in Ontario, Canada and elsewhere in North America about the relative benefits of single stream recycling versus two stream recycling. While a number of larger municipalities have moved to single stream recycling, the success of these programs has been mixed. Key issues with the program include:

- Concerns from end markets over product quality, particularly from the fibres end markets;

- Increased quantities of residues having to be managed in the Material Recovery Facility (MRF); and

- Labour costs, and thus overall processing costs in excess of expectations.

A number of municipalities in Ontario with populations in excess of 500,000 that generate upwards of 50,000 tonnes of recyclables per year and looking to their next round of recyclables collection and processing contracts are still interested in knowing the preferred approach. This study examined large-scale recyclables programs in Ontario, including three single stream and five two stream programs, comparing:

- Gross and net collection and processing costs;

- Recovery rates; and

- Implications on revenues.

\section{Review of current recycling collection and processing costs, net of revenue}

It can be difficult to compare program costs across municipalities considering the variances in materials collected and, more importantly, the demographics of each of the programs. For the purposes of the review herein, the three largest single stream programs (Programs 1 to 3 ) and the five largest two stream programs (Programs 4 to 8 ) were chosen to try to minimize the variances.

Even at that, the three single stream programs are also the three largest urban municipalities in the province, with the vast majority in each living in urban or suburban settings. The five two stream programs, with one exception have a combination of urban, suburban and rural residents typically translating into higher collection costs due to the greater distances having to be covered to service all households. The variances in the demographics of the programs, along with the economies of scale associated with the three single stream programs compared to the two stream programs, will be discussed further later in the paper.

Outlined in Table 1 are the costs for the three single stream programs in 2003 and in 2006. In 2003, Programs 1 to 3 were two stream. 2006 represents the first year in which all three had been operating as single stream programs for a minimum of one year. Note that in Table 1, even after accounting for inflation, the average cost for the single stream programs was higher than when they were two stream programs in 2003. 
Table 2 presents the costs for the five two stream programs over the same period. The difference in cost per tonne and cost per household between the one stream and two stream programs is presented at the bottom of Table 2.

Table 1: $\quad$ Single stream program costs -2003 and 2006.

\begin{tabular}{|c|c|c|c|c|c|c|c|c|c|c|}
\hline \multirow{3}{*}{ Municipality } & \multicolumn{10}{|c|}{2003} \\
\hline & \multirow{2}{*}{$\begin{array}{c}\text { Quantity } \\
\text { Tonnes }\end{array}$} & \multicolumn{4}{|c|}{ Cost Per Tonne } & \multirow[t]{2}{*}{ Households } & \multicolumn{4}{|c|}{ Cost Per HH } \\
\hline & & & Gross & & Net & & & Gross & & Net \\
\hline \multicolumn{11}{|c|}{ Single Stream Programs (Two Stream in 2003) } \\
\hline Program 1 & 43,516 & $\$$ & 241.39 & $\$$ & 141.59 & 253,700 & $\$$ & 41.41 & $\$$ & 24.29 \\
\hline Program 2 & 82,231 & $\$$ & 224.00 & $\$$ & 147.66 & 331,000 & $\$$ & 55.65 & $\$$ & 36.68 \\
\hline Program 3 & 148,798 & $\$$ & 213.36 & $\$$ & 126.46 & 959,000 & $\$$ & 33.10 & $\$$ & 19.62 \\
\hline \multicolumn{2}{|l|}{ Average } & $\$$ & 220.99 & $\$$ & 135.21 & & $\$$ & 39.30 & $\$$ & 24.05 \\
\hline
\end{tabular}

\begin{tabular}{|c|c|c|c|c|c|c|c|c|c|c|}
\hline \multirow{3}{*}{ Municipality } & \multicolumn{10}{|c|}{2006} \\
\hline & \multirow{2}{*}{$\begin{array}{c}\text { Quantity } \\
\text { Tonnes }\end{array}$} & \multicolumn{4}{|c|}{ Cost Per Tonne } & \multirow[t]{2}{*}{ Households } & \multicolumn{4}{|c|}{ Cost Per HH } \\
\hline & & & Gross & & Net & & & Gross & & Net \\
\hline \multicolumn{11}{|c|}{ Single Stream Programs } \\
\hline Program 1 & 71,147 & $\$$ & 286.87 & $\$$ & 192.20 & 277,400 & $\$$ & 73.57 & $\$$ & 49.29 \\
\hline Program 2 & 100,022 & $\$$ & 246.03 & $\$$ & 145.37 & 376,300 & $\$$ & 65.40 & $\$$ & 38.64 \\
\hline Program 3 & 176,760 & $\$$ & 236.18 & $\$$ & 127.05 & $1,050,600$ & $\$$ & 39.74 & $\$$ & 21.38 \\
\hline \multicolumn{2}{|l|}{ Average } & $\$$ & 249.38 & $\$$ & 145.64 & & $\$$ & 50.91 & $\$$ & 29.73 \\
\hline
\end{tabular}

\begin{tabular}{|l|rr|r|r|rr|rr|}
\hline Cost Increase 2003 to $2006(1)$ & $\$ 14.86$ & $\$$ & 2.16 & & $\$$ & 9.20 & $\$$ & 4.21 \\
\cline { 2 - 7 } & & $6.3 \%$ & $1.5 \%$ & & $22.1 \%$ & $16.5 \%$ \\
\hline
\end{tabular}

(1) Accounting for $2 \%$ inflation per year, compounded from 2003 to 2006 .

Table 2: $\quad$ Two stream program costs -2003 and 2006.

Two Stream Programs

\begin{tabular}{|c|c|c|c|c|c|c|c|c|c|c|}
\hline \multirow{3}{*}{ Municipality } & \multicolumn{10}{|c|}{2003} \\
\hline & \multirow{2}{*}{$\frac{\text { Quantity }}{\text { Tonnes }}$} & \multicolumn{4}{|c|}{ Cost Per Tonne } & \multirow[t]{2}{*}{ Households } & \multicolumn{4}{|c|}{ Cost Per HH } \\
\hline & & & Gross & & Net & & & oss & & let \\
\hline Program 4 & 26,977 & $\$$ & 205.59 & $\$$ & 91.57 & 170,500 & $\$$ & 32.52 & $\$$ & 14.49 \\
\hline Program 5 & 33,988 & $\$$ & 139.85 & $\$$ & 113.57 & 143,300 & $\$$ & 33.16 & $\$$ & 26.93 \\
\hline Program 6 & 38,491 & $\$$ & 189.49 & $\$$ & 90.10 & 177,700 & $\$$ & 41.04 & $\$$ & 19.52 \\
\hline Program 7 & 30,780 & $\$$ & 283.59 & $\$$ & 162.53 & 194,200 & $\$$ & 44.94 & $\$$ & 25.75 \\
\hline Program 8 & 23,712 & $\$$ & 184.27 & $\$$ & 67.52 & 121,000 & $\$$ & 36.12 & $\$$ & 13.24 \\
\hline Average & & $\$$ & 199.36 & $\$$ & 106.54 & & $\$$ & 38.04 & $\$$ & 20.33 \\
\hline
\end{tabular}

\begin{tabular}{|c|c|c|c|c|c|c|c|c|c|c|}
\hline \multirow{3}{*}{ Municipality } & \multicolumn{10}{|c|}{2006} \\
\hline & \multirow{2}{*}{$\begin{array}{l}\text { Quantity } \\
\text { Tonnes }\end{array}$} & \multicolumn{4}{|c|}{ Cost Per Tonne } & \multirow[t]{2}{*}{ Households } & \multicolumn{4}{|c|}{ Cost Per HH } \\
\hline & & & Gross & & Net & & & oss & & let \\
\hline Program 4 & 37,876 & $\$$ & 255.50 & $\$$ & 131.15 & 171,900 & $\$$ & 56.29 & $\$$ & 28.89 \\
\hline Program 5 & 41,293 & $\$$ & 154.17 & $\$$ & 125.79 & 156,700 & $\$$ & 40.64 & $\$$ & 33.16 \\
\hline Program 6 & 49,478 & $\$$ & 230.44 & $\$$ & 133.58 & 199,500 & $\$$ & 57.15 & $\$$ & 33.13 \\
\hline Program 7 & 39,343 & $\$$ & 286.33 & $\$$ & 181.24 & 203,200 & $\$$ & 55.44 & $\$$ & 35.09 \\
\hline Program 8 & 26,420 & $\$$ & 213.83 & $\$$ & 94.32 & 150,800 & $\$$ & 37.47 & $\$$ & 16.53 \\
\hline Average & & $\$$ & 228.18 & $\$$ & 135.76 & & $\$$ & 50.29 & $\$$ & 29.92 \\
\hline
\end{tabular}

\begin{tabular}{|c|c|c|c|c|c|c|c|}
\hline \multirow[t]{2}{*}{ Cost Increase 2003 to 2006 (1) } & $\$$ & 16.61 & 22.70 & $\$$ & 9.92 & $\$$ & 8.35 \\
\hline & & $7.9 \%$ & $20.1 \%$ & & $24.6 \%$ & & $38.7 \%$ \\
\hline 20061 Stream to 2 Stream Difference & $-\$$ & 21.20 & 9.88 & $-\$$ & 0.62 & $\$$ & 0.19 \\
\hline 2 Stream \%'age less than 1 Stream & & $-8.5 \%$ & $-6.8 \%$ & & $-1.2 \%$ & & $0.6 \%$ \\
\hline
\end{tabular}

(1) Accounting for $2 \%$ inflation per year, compounded from 2003 to 2006 
Comparing the 2006 results shows that two stream programs have a net cost per tonne almost $\$ 10$ lower than single stream programs. However, on a cost per household basis, the net cost of all programs is identical.

A number of things should be noted when comparing the results. First, all of the single stream programs are operating with new infrastructure. However, with the exception of one of the two stream programs, the other programs are operating with older technologies, which will not be sustainable over the long term - all will increase with the establishment of new infrastructure. The cost increase will be dependent on the processing technologies chosen but typically would range in cost between $\$ 15$ and $\$ 20$ per tonne for the capital amortized over 10 years and monetized over 35,000 to 50,000 tpy. Some of this higher capital cost would be offset by lower labour costs as newer optical sorting technologies are added to the facility. This typically saves $\$ 3$ to $\$ 5$ per tonne again assuming a 35,000 to 50,000 tpy facility, operating over one shift.

The net increase in cost to the two stream facilities would be in the order of $\$ 10$ to $\$ 17$ per tonne. Adding $4 / 5$ of this increase (as one two stream program already has a new MRF) to the costs shown would result in overall two stream program costs increasing to approximately $\$ 144$ to $\$ 152$ per tonne, approximately $\$ 2$ per tonne less to $\$ 6$ per tonne more than single stream programs.

Secondly, two of the large single stream programs receive a fibre premium for their materials. This is something they negotiated with the contractor who actually buys the fibres from the municipality and then sells them to the end markets, i.e., the municipality does not sell directly to the end market. Across the three programs (only two of which receive a fibre premium), the premium equates of approximately $\$ 6$ to $\$ 7$ per tonne (i.e., comparing programs on an equal revenue stream basis, the two stream programs would be $\$ 6$ to $\$ 7$ per tonne lower than indicated).

Table 3: Comparison of single stream to two stream costs with adjustments.

\begin{tabular}{|c|c|c|c|c|c|}
\hline \multirow{3}{*}{ Single Stream Program Costs (From Table 2-1) } & \multirow{3}{*}{\begin{tabular}{r|} 
Average \\
Quantity (te) \\
115,977 \\
\end{tabular}} & \multicolumn{4}{|c|}{ Net Cost (Average) } \\
\hline & & \multicolumn{2}{|c|}{ Low } & \multicolumn{2}{|c|}{ High } \\
\hline & & $\$$ & 145.64 & $\$$ & 145.64 \\
\hline Two Stream Program Costs (From Table 2-2) & 38,882 & $\$$ & 135.76 & $\$$ & 135.76 \\
\hline Adjustment for New Capital & & $\$$ & 10.00 & $\$$ & 17.00 \\
\hline Adjustment for Premium Fibre Revenues & & $-\$$ & 7.00 & $-\$$ & 6.00 \\
\hline Adjustment for Economies of Scale & & $-\$$ & 8.50 & $-\$$ & 5.00 \\
\hline Adjusted Two Stream Program Costs & & $\$$ & 130.26 & $\$$ & 141.76 \\
\hline 20061 Stream to 2 Stream Difference & & $\$$ & 15.38 & $-\$$ & 3.88 \\
\hline 2 Stream \%'age less than 1 Stream & & & $-10.6 \%$ & & $-2.7 \%$ \\
\hline
\end{tabular}

Finally, it is generally accepted that there are economies of scale associated with recyclables processing. With the larger facilities (greater than 50,000 tpy), processing typically occurs over more than one shift per day, which means that capital costs are monetized over two shifts and more tonnes, thereby lowering the capital cost per tonne. Therefore, lower overall operating costs are expected 
with larger facilities. Monetizing capital over 70,000 to 100,000 tpy rather than 35,000 to 50,000 tpy would reduce capital costs by $\$ 5$ and $\$ 8.50$ per tonne, i.e., single stream programs operating at a higher throughput could potentially save $\$ 5$ to $\$ 8.50$ per tonne.

Adding up these additional costs and the potential savings, the result suggests that two stream programs in Ontario enjoy an even greater cost advantage over single stream programs (Table 3).

Combined, even with accounting for the differences in the programs, two stream programs still show a savings per tonne of between approximately $\$ 4$ and $\$ 15$ or $3 \%$ to $11 \%$ when compared to single stream programs.

\section{Impact on diversion rates moving to single stream recycling}

It is difficult to exactly quantify the impact moving to single stream has on diversion rates for recycling. Typically, all municipalities report an increase in the quantity of material arriving at the MRF as a result of moving to single stream however, the increase may not be solely due to the single stream collection system rather to a combination of factors such as increased promotion, bag limits, user pay, etc. Overall, there is no clear evidence that the implementation of single stream recycling itself is the main basis for increased diversion rates.

It is clearly understood that providing more education and promotion to the public will result in an increase in diversion rates. Reminding people of the program, advertising and even promotion of diversion at work, schools, etc., serve to increase diversion through existing programs. However, even with increased public education and promotion, the increase in diversion still relies on voluntary actions on the part of residents.

Anytime there is a change in a program, whether it is to add a box, add new materials, change the collection system or move to single stream, there is a requisite increase in the quantity of material collected at the curb because the change reminded people about the program.

One of the most effective ways of increasing diversion is to implement a form of restrictive garbage bag/container limits (two or less per week per household) alone or in combination with reduced collection frequency and even to a full user pay system for garbage. Garbage bag limits and a move to a biweekly collection program for garbage in one large Ontario municipality resulted in a $30-40 \%$ increase in recyclables collected at the curb. It is questionable as to whether a move to single stream would actually increase diversion anymore as that municipality is now reporting $65 \%$ diversion in those municipalities with biweekly garbage collection, weekly recyclables and weekly organics collection.

\subsection{Quantity diverted from single stream and two stream programs in Ontario}

With single stream recycling, the total quantity of materials arriving at the MRF does indeed in most instances increase. However, after accounting for increase in residues, the total quantity diverted may or may not increase. Currently there 
is limited data to specifically state that single stream recycling will result in increased diversion.

The three major municipalities in the province that employ single stream recycling saw the quantity of recyclables managed increase by approximately 15\% per household between 2003 and 2006 (Table 4). However, over the same period, municipalities employing a two stream system increased their recovery rates by almost $21 \%$. More importantly, the total quantity of material collected per household was more than $10 \%$ higher in two stream municipalities than in those under a single stream program (Table 5).

Table 4: Recovery rates from single stream (SS) recycling programs in Ontario.

\begin{tabular}{|c|c|c|c|c|}
\hline Municipality & \multicolumn{2}{|c|}{ Households } & \multicolumn{2}{|c|}{ Quantity/HH } \\
\hline & $\begin{array}{l}2003 \text { (pre- } \\
\text { SS) }\end{array}$ & $\begin{array}{l}2006 \text { (post- } \\
\text { SS) }\end{array}$ & $\begin{array}{l}2003 \text { (pre- } \\
\text { SS) }\end{array}$ & $\begin{array}{c}2006 \text { (post-SS) (+/- } \\
\%)\end{array}$ \\
\hline Program 1 & 264,400 & 277,400 & $171.5 \mathrm{~kg}$ & $256.5 \mathrm{~kg}(+49.5 \%)$ \\
\hline Program 2 & 340,000 & 376,300 & $248.4 \mathrm{~kg}$ & $265.8 \mathrm{~kg}(+7.0 \%)$ \\
\hline Program 3 & 980,200 & $1,050,600$ & $155.2 \mathrm{~kg}$ & $168.3 \mathrm{~kg}(+8.4 \%)$ \\
\hline Weighted Avg & & & $177.9 \mathrm{~kg}$ & $204.1 \mathrm{~kg}(+14.8 \%)$ \\
\hline
\end{tabular}

Table 5: Recovery rates from two stream recycling programs in Ontario*.

\begin{tabular}{|l|c|c|c|c|}
\hline Municipality & \multicolumn{2}{|c|}{ Households } & \multicolumn{2}{c|}{ Quantity/HH } \\
\hline & $\mathbf{2 0 0 3}$ & $\mathbf{2 0 0 6}$ & $\mathbf{2 0 0 3}$ & $\mathbf{2 0 0 6}(\%+/-)$ \\
\hline Program 4 & 170,500 & 171,900 & $158.2 \mathrm{~kg}$ & $220.3 \mathrm{~kg}(+39.2 \%)$ \\
\hline Program 5 & 143,300 & 156,700 & $237.1 \mathrm{~kg}$ & $263.6 \mathrm{~kg}(+11.2 \%)$ \\
\hline Program 6 & 177,700 & 199,500 & $207.9 \mathrm{~kg}$ & $248.2 \mathrm{~kg} \mathrm{(+19.4 \% )}$ \\
\hline Program 7 & 194,200 & 203,200 & $158.5 \mathrm{~kg}$ & $193.6 \mathrm{~kg}(+22.0 \%)$ \\
\hline Program 8 & 121,000 & 150,800 & $196.2 \mathrm{~kg}$ & $175.2 \mathrm{~kg}(-10.6 \%)$ \\
\hline Weighted Avg & & & $189.9 \mathrm{~kg}$ & $\mathbf{2 2 9 . 7} \mathbf{~ k g ~ ( + 2 0 . 9 \% )}$ \\
\hline
\end{tabular}

*Program 8 is not included in the dataset as the fire in 2006 resulted in a lower tonnage being reported as diverted.

One of the large single stream programs has a large percentage of their population in multi-family dwellings, which would account somewhat for the lower recovery rate. Recovery rates for Programs 1 to 3 would be expected to have somewhat higher recovery rates as a result of the large number of large daily newspapers not typically found in the same quantities in the smaller two stream programs. This is a factor considering recovery rates for newspapers on average exceed $90 \%$ for most Ontario municipalities.

Comparing the data in Tables 4 and 5 suggest that there may be little to no benefit of moving from two stream collection to single stream collection with respect to the quantity of material that could be diverted from disposal.

\section{Revenue implications of moving to single stream}

There are two factors to consider when examining the revenue implications of moving to single stream recycling: 
- Downgrades of \#8 newspaper as a result of poor quality; and

- Revenue losses through the inadvertent marketing of prohibitives (plastics, metal, glass and other non-fibre materials) in the ONP (newspaper) bale.

\subsection{Fibre quality}

The fibres end markets have been concerned about the quality of fibres coming from single stream MRFs since they were first introduced more than five years ago. The concern is more about the prohibitives rather than the outthrows (i.e., non-newspaper compatible fibres including OCC, boxboard and telephone directories), although outthrows themselves are an issue. Figure 1 shows an example of the issue facing the end markets.

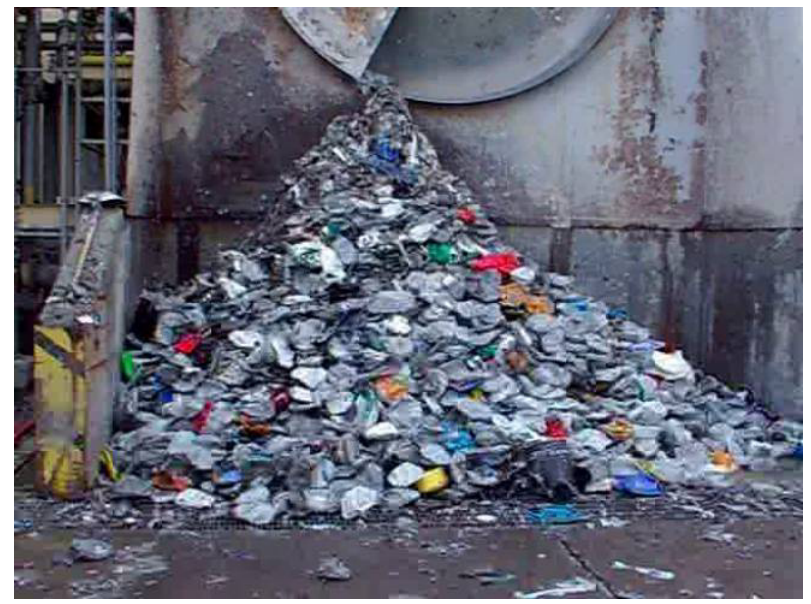

Courtesy of NORPAC, July 2006

Figure 1: Outthrows from the end of the mill process - pulper rejects.

Overall, the mills indicated the following concerns with single stream sourced fibres:

Deinking Mills:

- $\quad$ Reject rate increase; Increased bleaching costs; increased biocide costs (increased organic content of fibres); increased labour cost to handle additional fibre and pulper rejects; increased maintenance costs; increased landfill costs; reduced capacity (downtime for maintenance and cleaning); and contaminants reducing the pulping rate.

Paper-making Machine:

- Increased stickies and related machine downtime for cleanup; and negative impacts on product quality (spots on paper, brightness).

Mills have reported that residue rates/yield losses from single stream programs average $10-15 \%$ with the worst programs exceeding more than $25 \%$. An early study by the American Forest Products Association suggested that added mill costs as a result of accepting fibres from single stream materials were $\$ 9$ per tonne. 
The results of these higher yield losses and higher residues have not to date been reflected in lower revenues to municipalities for their newspaper. This is a result of the high demand for ONP coming from overseas markets and a decreasing generation rate for newspaper. However, at a recent Paper and Paperboard Environmental Council (PPEC) Paper Forum, the mills present expressed concerns about the quality of fibres coming from Ontario MRFs and that the condition is not sustainable in the long term. In speaking with mill representatives, it was expressed that in the near term the value of fibres from single stream programs may be downgraded to a "single stream \#8 ONP" and be valued at \$20 per tonne less than "two stream \#8 ONP".

Considering that approximately $60 \%$ of all tonnes marketed from a MRF are newspaper, this is significant. For example, examining the quantity of ONP managed by Program 4, the lost revenues could total almost $\$ 400,000$ annually. Across all ONP marketed in Ontario, if all programs moved to single stream and were downgraded, the financial cost would exceed $\$ 8.9$ million.

\subsection{Containers inadvertently in the ONP bale}

Inadvertently, with the high prohibitives rate in single stream sourced ONP, a lot of valuable material is sent to paper mills. Containers end up going to the fibre mill instead of the respective container end markets. This means that although revenues equal to the value of ONP are received for these materials, respecting that containers generally all have higher end market values than fibres, this is a significant loss in potential revenues. Using just $5 \%$ as the average outthrows percentage in single stream \#8 ONP, about one half the general average, assuming that the mix of materials lost is equal to the average mix of containers marketed by Program 4 (as an example), the implications on lost revenues would be approximately as follows (Table 6).

Table 6: $\quad$ Estimated lost revenue to containers in the ONP.

\begin{tabular}{|c|c|c|c|}
\hline Material & $\begin{array}{l}\text { Quantity } \\
\text { (Tonnes) }\end{array}$ & $\begin{array}{l}\text { Value Per } \\
\text { Tonne (1) }\end{array}$ & $\begin{array}{c}\text { Lost } \\
\text { Revenue }\end{array}$ \\
\hline Aluminum & 45 & $\$ 2,169$ & $\begin{array}{l}\$ \$ 97,605 \\
\end{array}$ \\
\hline PET & 198 & 369 & 73,062 \\
\hline HDPE & 126 & 506 & 63,756 \\
\hline Steel Cans & 150 & 173 & 25,950 \\
\hline Clear Glass & 78 & 35 & 2,730 \\
\hline Coloured Glass & 77 & $\$$ & $\$$ \\
\hline 3-Mix Glass & 141 & 31 & 4,371 \\
\hline Tubs \& Lids & 33 & 144 & 4,752 \\
\hline Mixed Plastics & 23 & 144 & 3,312 \\
\hline Polycoat/Aseptic & 11 & 89 & 979 \\
\hline Polystyrene & 23 & 75 & 1,725 \\
\hline Plastic Film & 76 & 54 & 4,104 \\
\hline Totals & 981 & 279 & $\$ 273,604$ \\
\hline \begin{tabular}{|l|} 
Revenue from ONP \\
\end{tabular} & 981 & 122 & $\$ 119,682$ \\
\hline \multicolumn{3}{|l|}{ Net Loss } & $\$ 153,922$ \\
\hline
\end{tabular}

(1) Based on CSR Price Sheet, Average 2006 
In total, almost $\$ 154,000$ would be "lost" assuming that the 981 tonnes ended up being "sold" as newspapers received the average of $\$ 122$ per tonne rather than being sold for each material's true value at an average real worth of the materials of an estimated $\$ 279$ per tonne. Extrapolating this across Ontario, the total value of the lost containers would equate to more than $\$ 3.5$ million. Making matters worse is that the fibre mills in the province indicate that they do not recover any material from the pulpers, rather all rejected materials end up going to landfill, with the result being that real recovery rates for recycling programs in Ontario being lower than reported.

\section{Possible solutions - single stream in the future}

One Ontario facility recently installed optical sorting on their fibres line in hopes that it would improve the quality of the ONP being sent to end markets and reduce the sorting staff requirements. In initial pre-installation material audits, prohibitive rates in the ONP bale were approximately $10 \%$; typical of most single stream plants.

The end markets, concerned over rising costs indicated that if improvements in product quality were not made, the facility could expect the price paid for ONP to drop by up to $\$ 20$ per tonne. The facility, in cooperation with Stewardship Ontario, investigated alternatives for improving the quality of the ONP stream, which would help guarantee future market value to the municipality, while decreasing processing costs, with the savings being shared with the municipality.

Investigations were made with optical sorting equipment suppliers in North America and Europe. Facilities within North America and Europe were visited to examine optical sorting technologies for fibres. After these investigations, it was determined that the best approach was not to use the optical sorting to remove a clean stream of ONP, rather to use the technology to remove all unwanted materials from the ONP.

The result was the procurement of two dual-eject optical sorting machines. The first eject was for all prohibitives, including all plastics (film included), metals and glass. The second eject was for all browns, including old corrugated containers (OCC) and old boxboard (OBB). The remaining materials would be negatively sorted and be transferred to a short quality control line where any missed materials would be removed manually by sorting staff.

Initial results from the audits post-installation show mixed results. The quality of the ONP has improved by less than $10 \%$ in early results. The cost to achieve these results has improved however, with the number of sorters required dropping by more than $50 \%$.

As this is the first installation of its kind in North America managing such a mix of materials, considering it has only been in operation for approximately three months, it is not possible to draw definitive conclusions about its effectiveness. Although there has been a decrease in the cost, ONP product quality has not significantly improved. Therefore, the concerns of the ONP mills have yet been addressed. Downgrades could still occur in the near future with 
resulting decreases in revenue. Ongoing adjustments to the equipment and ongoing audits will ultimately determine its effectiveness at improving fibre quality at a reduced cost.

\section{Conclusions}

With the collection of recyclables tending to move back to weekly from biweekly as municipalities continue to decrease garbage collection services and recyclables volumes continue to increase, alternating week collection system with fibres in the first week and containers in the second, provides collection costs similar to single stream collection, i.e., the cost advantage of single stream recyclables collection is lost. Therefore, processing single stream recyclables has to become more cost effective.

The August 2007 issue of Resource Recycling summarizes the issues in single stream recycling in a single line, "Processing facilities, however, have not yet perfected the intricacies of disassembling this mix of materials" (page 30). Making matters worse for Ontario programs is that they collect and process many more materials than are typically managed in US based programs (e.g., tubs and lids, polystyrene, polycoat, aseptics, plastic film, polystyrene).

Discussions with manufacturers suggest that in a typical single stream MRF the efficiency of the front-end processing, separating the fibres from containers, is only about $80-85 \%$. In other words, $15-20 \%$ of the fibres end up on the containers line and $15-20 \%$ of the containers end up on the fibres line. This results in additional requirements for screening and/or sorting staff to clean up and sort the materials to meet end market specifications. This carries a high cost; higher than doing two sorts at the curb.

Advances in optical sorting technologies for containers, and more recently fibres, can result in fewer sorting staff and lower overall processing costs, although two stream MRFs can also benefit from optical sorting for containers to reduce costs.

In summary, with increased processing costs and the lost revenues in total exceeding collection savings in most instances (and zero under alternating week collection), overall, single stream recycling at this point does not show the cost advantage that was originally anticipated.

\section{References}

[1] Ontario Waste Diversion Organization 2006 Municipal Financial and Tonnage Reports, http://www.wdo.ca/reports/Default.aspx

[2] Norpac, Personal communication, July 2006.

[3] Abitibi-Bowater and Atlantic Packaging, Personal communication, December 2007.

[4] American Forest \& Paper Association, "Paper Recycling: Quality is Key to Long-term Success", March 2004. 